\title{
Milliequivalent per Deciliter
}

National Cancer Institute

\section{Source}

National Cancer Institute. Milliequivalent per Deciliter. NCI Thesaurus. Code C67473.

A concentration unit measured as a number of milliequivalents of solute per deciliter of solution. 